Article

\title{
Analysis of the Oscillation Behavior of Hybrid Aluminum/Steel Joints Realized by Ultrasound Enhanced Friction Stir Welding
}

\author{
Marco Thomä ${ }^{1, *(D)}$, Andreas Gester ${ }^{1}$, Guntram Wagner ${ }^{1}\left[\right.$ and Marco Fritzsche ${ }^{2}$ \\ 1 Chair of Composites and Material Compounds, Institute of Materials Science and Engineering, \\ Chemnitz University of Technology, 09111 Chemnitz, Germany; andreas.gester@mb.tu-chemnitz.de (A.G.); \\ guntram.wagner@mb.tu-chemnitz.de (G.W.) \\ 2 Polytec GmbH, 76337 Waldbronn, Germany; m.fritzsche@polytec.de \\ * Correspondence: marco.thomae@mb.tu-chemnitz.de; Tel.: +49-371-531-315-22
}

Received: 3 July 2020; Accepted: 6 August 2020; Published: 10 August 2020

\begin{abstract}
Friction stir welding (FSW) is an innovative solid-state joining process, which is suitable for joining dissimilar materials with strongly differing physical and chemical properties such as aluminum and steel. Where other joining methods such as fusion welding struggle to achieve appropriate joint strengths due to the excessive formation of brittle aluminum-rich intermetallic phases (IMP), FSW joints of aluminum and steel only show small layers of IMP, thus, sufficient tensile strengths in proximity to the maximum tensile strength of the weaker aluminum base material can be reached. With the aim to optimize the mechanical and microstructural properties of such dissimilar joints for widening the field for possible industrial applications, several hybrid friction stir welding methods have been developed which include an additional energy input, whereas the ultrasound enhancement (USE-FSW) is one of the most promising. The current work was carried out on AA6061/DC04 joints which were successfully friction stir welded with and without ultrasound support, in respect to the influence of varying the ultrasound transmission side. The functionality of the USE-FSW setup could be verified by multi point laser vibrometer measurements. Additionally, a higher proportion of transversal oscillation for the transmission of power ultrasound into aluminum could be detected using a scanning vibrometer. In comparison to the conventionally friction stir welded joints the ultrasound enhancement led to an avoidance of weld defects and an increase of the steel particle volume in the stir zone. The joint produced with power ultrasound transmission via aluminum resulted in a more uniform interface.
\end{abstract}

Keywords: friction stir welding; ultrasound enhancement; aluminum/steel joints; oscillation behavior; mechanical and microstructural properties

\section{Introduction}

Since its invention at The Welding Institute in 1991 friction stir welding developed rapidly to a standardized joining method for similar aluminum/aluminum joints [1,2]. Friction stir welding (FSW) is also advantageous for dissimilar joints due to the low process temperatures, which avoid complete melting of the base materials, hence qualifying as a solid-state joining process [3]. The process of friction stir welding is characterized by a rotating cylindrical tool with a shoulder and a probe, which gets pressed on the surface of the joining partners. The resulting friction-based heating of the materials enables the probe to plunge into the plasticized base materials until the shoulder gets in contact. Subsequently, the rotation of the tool is superimposed by a translational movement, causing the plasticized materials to be stirred around the probe, leading to an adhesive bonded joint [4]. 
Several investigations verified the capability of FSW for realizing dissimilar joints of the same base metal but different alloys [5,6], different metals with similar physical and chemical properties [7,8], different metals with dissimilar physical and chemical properties $[9,10]$ as well as metals with non-metals [11]. In this context friction stir welded aluminum/steel joints pose an important representative in the group of dissimilar joints with different physical and chemical properties, which can be found in several industrial fields such as shipbuilding (e.g. hull of the ship) or the automotive industry (e.g., front subframe Honda) [3,12]. Despite the use of the FSW technique for industrial applications of Al/St joints, the formation of brittle aluminum-rich intermetallic phases remains a big challenge, which cannot be avoided completely due to the negligible solution of iron into aluminum at low temperatures after cooling [13]. Most of the literature verified the presence of the $\eta$-phase $\left(\mathrm{Fe}_{2} \mathrm{Al}_{5}\right)$ and $\theta$-phase $\left(\mathrm{FeAl}_{3}\right)$ as continuous layers at the interface of the friction stir welded aluminum/steel joints, which are classified as aluminum-rich due to their aluminum content amounting to more than 50 at $\%[9,14]$. These intermetallic phases (IMP) act detrimentally on the mechanical properties of the joints when exceeding a certain thickness $[15,16]$. On the other hand, if the thickness of the intermetallics can be kept low, high tensile strengths can be achieved, as the diffusion-based IMP_-besides mechanical interlocking (for example by hooks)_form the main bonding mechanism for aluminum/steel joints consisting of metal bonding with larger amounts of covalent bonding [17]. The investigations of Watanabe and Wang et al. proved the possibility of achieving high tensile strengths for Al/St joints with comparably small intermetallic layers of about $750 \mathrm{~nm}$ by reaching $90 \%$ of the strength of the aluminum base material $[9,14]$. To improve these values and to push the borders of process limitations for the FSW of dissimilar aluminum/steel joints as well as similar material combinations, different approaches of hybrid friction stir welding processes have been developed such as electrical assistance, laser assistance, gas tungsten arc welding assistance, or power ultrasound assistance [18-21]. The electrically assisted FSW approach used by Ferrando et al. resulted in an additional material softening and increase of temperature [18]. Further investigations of Merklein et al. on dissimilar Al/St joints using laser assistance to preheat the steel joining partner led to an increased welding speed and reached about $80 \%$ of the tensile strength of the aluminum base material [19]. Similar findings were gained by Bang et al., who also detected a higher tensile strength by using a leading gas tungsten arc welding torch and additionally confirmed an enhanced material flow due to the auxiliary heat input [20]. Each of these three hybrid FSW processes are based on the additional heating of the joining partners, that seemed to be beneficial so far in the combination with optimized friction stir welding parameters but included the risk of a more pronounced growth of grains for similar metal joints or IMP for dissimilar metal joints. Therefore, the power ultrasound assisted FSW approach seems to be most promising due to the mechanical energy input caused by the ultrasound oscillation, which interacts in-process with oxides, developing and/or existing intermetallic phases and potentially breaking them up leading to higher monotonic and cyclic strengths [22]. Furthermore, the material flow can be increased, and the process forces can be reduced [23]. Thus, this poses a promising possibility for the controlled formation of IMP up to an optimized thickness leading to maximal joint strength amongst other advantages. Regarding the literature in this field, there are different approaches for the ultrasound transmission in the FSW process. By transmitting the power ultrasound perpendicular into the tool, Park could avoid irregularities, improving the weld quality and increasing mechanical properties for similar aluminum joints, whereas Tian et al. also recently reported positively influenced welding results for the same transmission approach on $\mathrm{Al} / \mathrm{Cu}$ joints, e.g., an increase in tensile strength of about $61 \%$ [24,25]. A similar transmission of power ultrasound into the tool was used by Amini et al., who integrated the ultrasonic horn into the spindle, so that the ultrasound oscillation acted in the same vertical direction as the friction stir welding tool leading to a reduction in the downward force of $25 \%$ as well as a slight increase in tensile strength while welding $\mathrm{Al} / \mathrm{Al}$ [23]. Other approaches are based on the transmission into the joining partners. Liu et al., for instance, used an ultrasonic horn, which was fixed on the spindle with an angle of $40^{\circ}$ and placed ahead of the FSW process by $20 \mathrm{~mm}$ [26]. By using this setup for the realization of similar aluminum/aluminum joints the additional power ultrasound resulted in a 
decrease of the grain size as well as an increase for the tensile strength. These findings were likewise proven by Tarasov et al., who found the same grain size reduction as well as a reduction of tensile stress in the welding direction for FSW joints of AA7475 realized by ultrasonic vibration assisted friction stir welding at which the power ultrasound got transmitted into the metal sheets by the backing plate [27]. As mentioned before for $\mathrm{Al} / \mathrm{Cu}$ joints the transmission of power ultrasound in parallel to the FSW process is beneficial for dissimilar metal joints, which is verified by the investigations of Strass et al. for $\mathrm{Al} / \mathrm{Mg}$ joints and Thomä et al. for $\mathrm{Al} / \mathrm{St}$ joints who used the approach of ultrasound enhanced friction stir welding leading to improved quasistatic and cyclic properties amongst other findings [22,28]. Beside all these different approaches for hybrid ultrasound assisted friction stir welding processes showing positive influence of the power of ultrasound for similar as well as dissimilar metal joints, there is still a lack of knowledge regarding the impact of the ultrasonic oscillation in detail. So far, a further publication of Tarasov used a laser Doppler vibrometer (LDV) to verify a steady distribution of the power ultrasound over a length of $25 \mathrm{~mm}$ while welding similar aluminum metal sheets [29]. Regarding this first publication in the field of quantifying the additional power ultrasound while using an ultrasound assisted FSW process, several questions remain unsolved such as the influence of the used clamping system, the difference in the longitudinal and transversal proportions of the oscillation amplitude, as well as the transmission of the ultrasound oscillation in the rear joining partner, especially for dissimilar joints.

Therefore, the aim of this paper is to investigate the oscillation behavior of dissimilar aluminum/steel joints via laser Doppler vibrometry for the friction stir welding process with ultrasound enhancement depending on the transmission side of the power ultrasound. Further, light microscopic investigations are carried out to determine the effect of the power ultrasound on the joint interface as well as the steel particle distribution in the stir zone and to verify the existence of correlations with the oscillation behavior.

\section{Materials and Methods}

The aluminum alloy AA6061 and the deep drawing steel DC04 were selected as base materials in a sheet geometry of $280 \mathrm{~mm} \times 100 \mathrm{~mm} \times 3 \mathrm{~mm}$. The chemical compositions of the used AA6061 and DC04 are given in Table 1, according to the specifications of the manufacturer (Alumeco, Leopoldshöhe, Germany, ThyssenKrupp, Radebeul, Germany).

Table 1. Chemical composition of the investigated materials.

\begin{tabular}{cccccccccc}
\hline Material & \multicolumn{10}{c}{ Elements (wt\%) } \\
\hline \multirow{2}{*}{$\mathrm{AA6061}$} & $\mathrm{Si}$ & $\mathrm{Fe}$ & $\mathrm{Cu}$ & $\mathrm{Mn}$ & $\mathrm{Mg}$ & $\mathrm{Cr}$ & $\mathrm{Zn}$ & $\mathrm{Ti}$ & $\mathrm{Al}$ \\
& 0.64 & 0.51 & 0.21 & 0.14 & 0.89 & 0.15 & 0.04 & 0.05 & $\mathrm{Bal}$. \\
\hline \multirow{2}{*}{$\mathrm{DC04}$} & $\mathrm{C}$ & $\mathrm{Si}$ & $\mathrm{Mn}$ & $\mathrm{P}$ & $\mathrm{S}$ & $\mathrm{Al}$ & $\mathrm{Ti}$ & $\mathrm{Nb}$ & $\mathrm{Fe}$ \\
& 0.041 & 0.015 & 0.3 & 0.01 & 0.0077 & 0.49 & 0.0007 & 0.0037 & $\mathrm{Bal}$. \\
\hline
\end{tabular}

A four-axis universal machining center DMU80T from DMG Mori (Bielefeld, Germany) was used to produce the friction stir welds with a length of $200 \mathrm{~mm}$. It was additionally equipped with four load cells from Kistler (Sindelfingen, Germany) to run the process force-controlled and used mechanical clamping systems in all three spatial directions to fix the metal sheets in a butt joint configuration. The steel DC04 was placed on the advancing side and the tool was based off tungsten reinforced with $1 \%$ lanthanum oxide with a shoulder diameter of $16 \mathrm{~mm}$, a probe length of $2.8 \mathrm{~mm}$, and a metric thread of M6. A lateral offset of the tool center axis of $3 \mathrm{~mm}$ into the aluminum was applied to minimize the contact of the probe with the steel for two reasons. The first one was to reduce the wear of the tool and the second reason was to highlight the effect of the power ultrasound. A general schematic of the hybrid method of ultrasound enhanced friction stir welding is shown in Figure 1. 


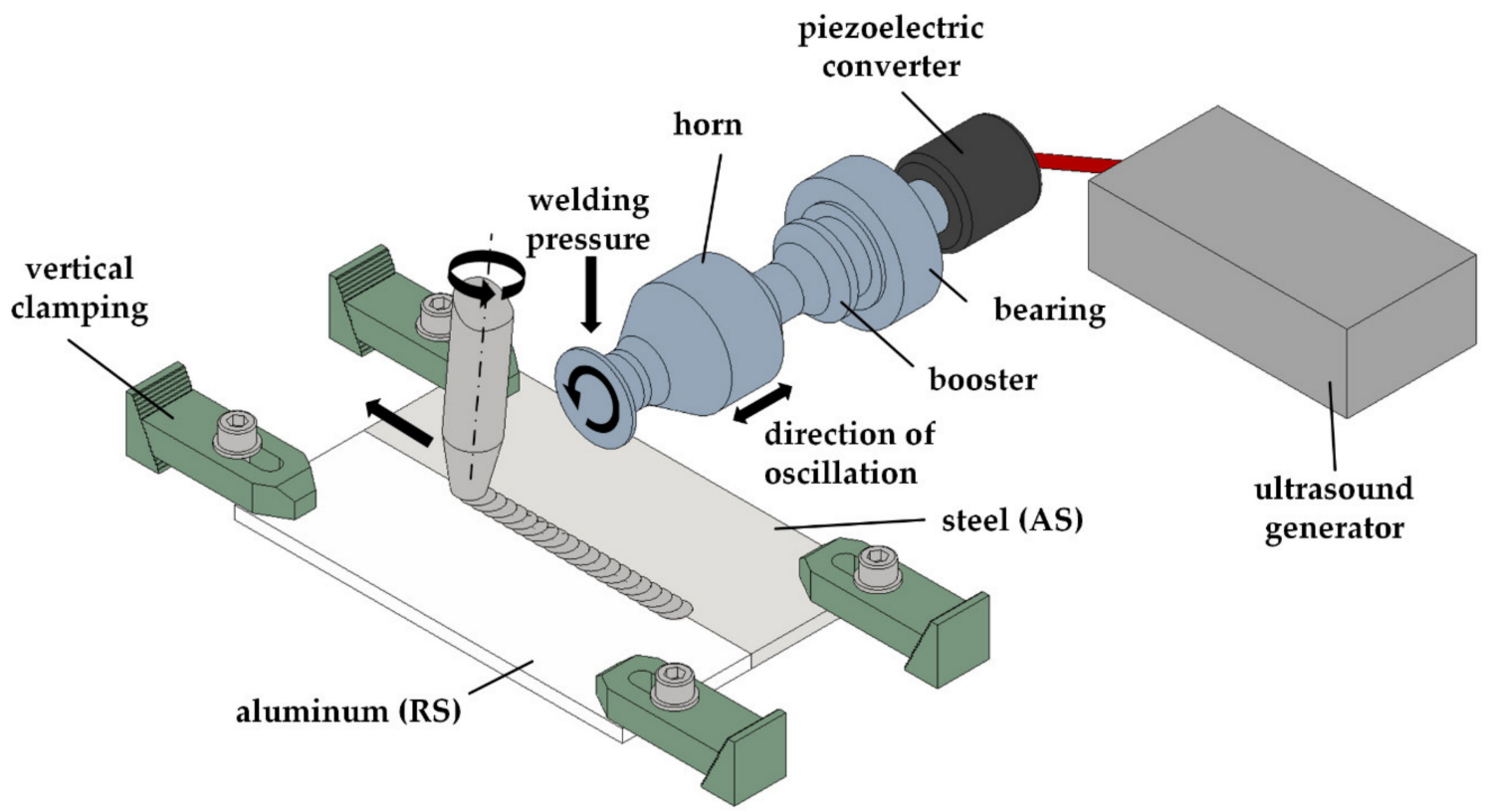

Figure 1. General setup of the ultrasound enhanced friction stir welding with exemplary clamping claws for the vertical fixation.

Supplementary an ultrasonic roll seam module RM20 of Schunk Sonosystems (Wettenberg, Germany) was integrated in the universal machining center with a transmission distance of $95 \mathrm{~mm}$, which corresponds to approximately a quarter of the ultrasound wave length in aluminum and steel representing the maximum displacement at the welding zone in theory. The roll seam module runs synchronously and in parallel to the friction stir welding tool during the process and transmits the power ultrasound with a resonance frequency of $20 \mathrm{kHz}$, a generator maximum power of $3000 \mathrm{~W}$, and a maximum amplitude of $38 \mu \mathrm{m}$ into one of the metal sheets via its horn. For the investigations, an amplitude of $21 \mu \mathrm{m}$ was chosen. Within the scope of the investigations, the transmission side of the power ultrasound via the horn was varied between steel and aluminum.

To study the oscillation behavior of the metal sheets in the pre-process when charged only with power ultrasound, laser Doppler vibrometry tests were carried out using two different setups and laser configurations (Figure 2).

The first setup is based on the synchronous measurement of 16 measurement points which are located next to the faying surfaces of the aluminum and steel sheets (Figure 2a) to investigate the oscillation behavior close to the welding zone depending on the position of the unrolling ultrasound horn. For this purpose an MPV-800 multi point vibrometer (Polytec GmbH, Waldbronn, Germany) equipped with 16 lasers was used, recording every measurement point simultaneously with a sampling rate of $500 \mathrm{kHz}$ one-dimensionally for the whole duration the horn required to unroll with a feed of $30 \mathrm{~mm} / \mathrm{min}$. This LDV measurement took place over a distance of $200 \mathrm{~mm}$ (corresponding to the subsequent length of the joints). The second setup consisted of the PSV-500-3D scanning vibrometer (Polytec $\mathrm{GmbH}$, Waldbronn, Germany), which operates with three single lasers, referenced by their angular relation to each other for determining the three-dimensional oscillation behavior of each scanning point (Figure 2b). For this three-dimensional scanning measurement, a static position of the power ultrasound transmission via the horn is necessary so that the scanning can take place. To investigate the influence of the clamping system the three static positions' plunging position, center of weld, and end hole position of the horn were chosen following the subsequent FSW process. For every static horn position, 790 points were scanned on the steel and aluminum metal sheets with a sampling rate of $200 \mathrm{kHz}$. 
Light microscopic investigations were carried out on a light microscope Olympus GX51 (Olympus Europe, Hamburg, Germany). The amount and size of particles in the aluminum/steel joints was determined by the systematic manual point count in accordance with ASTM E562.

\section{$\underline{1 D \text { multi point vibrometry }}$}

(a)

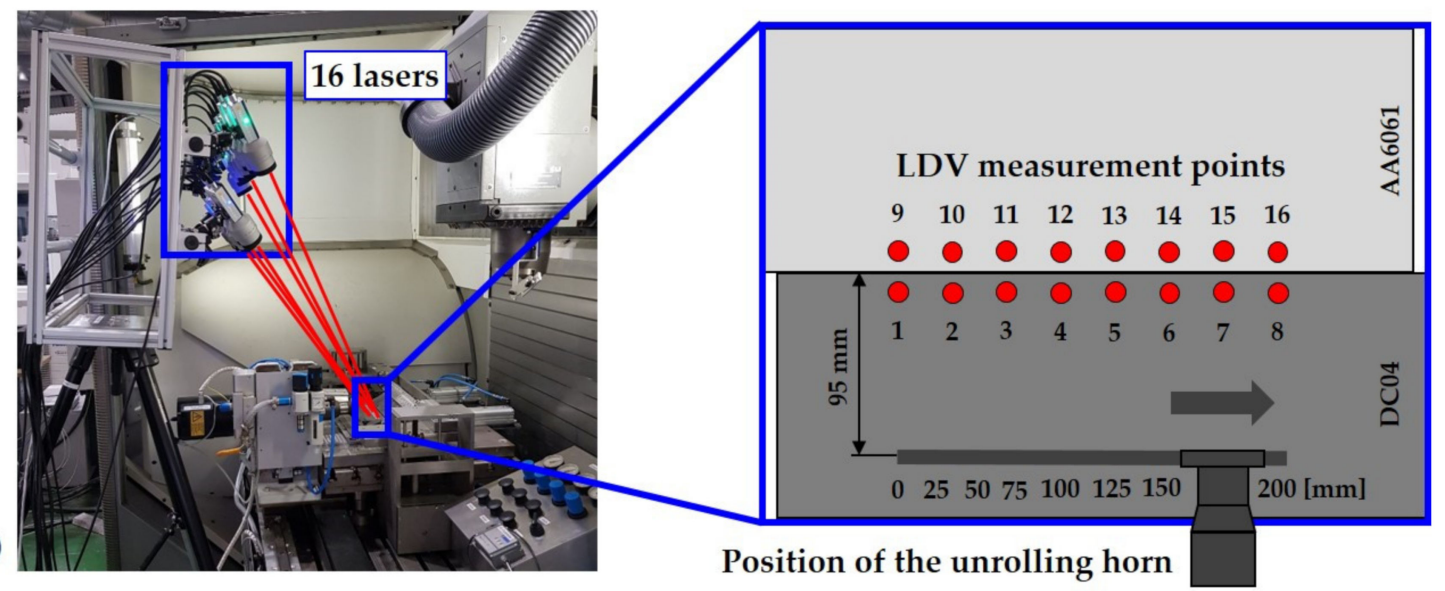

$\underline{\text { 3D scanning vibrometry }}$

(b)

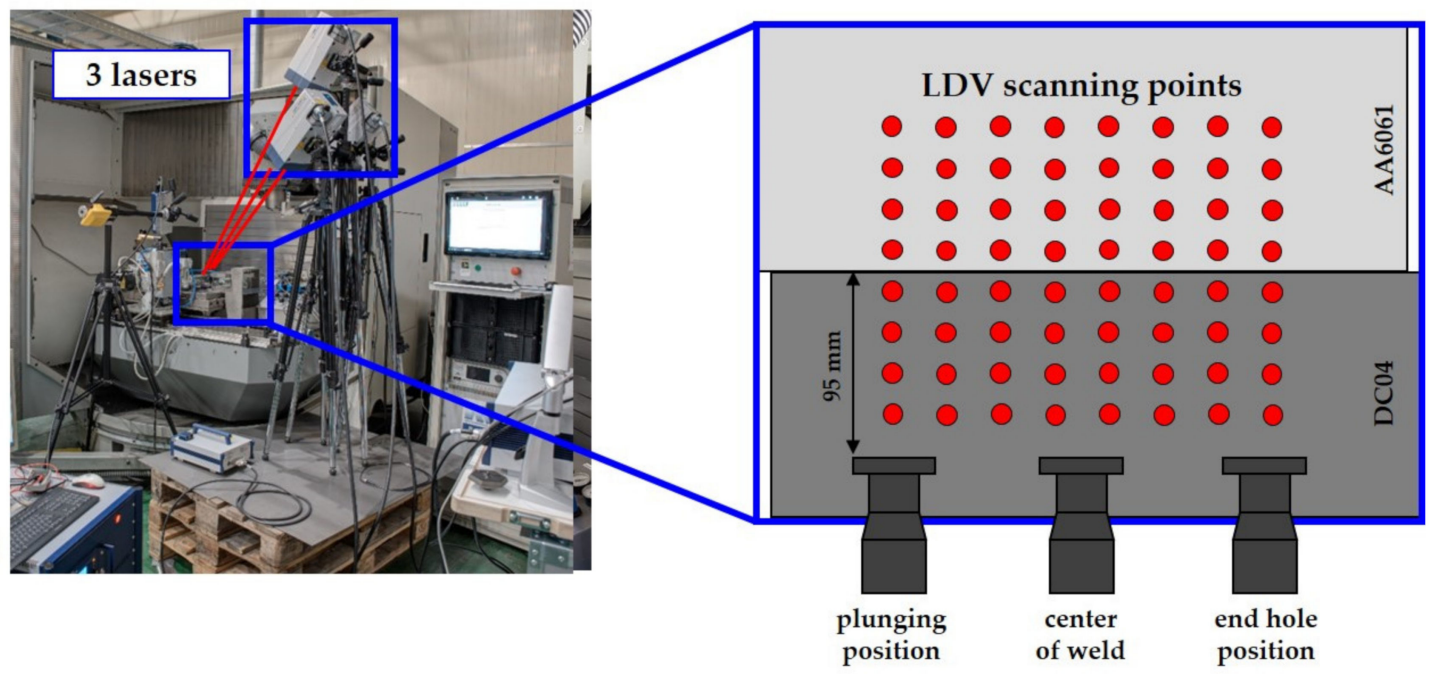

Figure 2. (a) Setup 1D multi point vibrometry with measurement points and position of the unrolling horn; (b) setup 3D scanning vibrometry with exemplary scanning points and static positions of the horn.

\section{Results and Discussion}

Within the scope of this research work, dissimilar joints of AA6061/DC04 could be realized by conventional friction stir welding as well as ultrasound enhanced friction stir welding. By varying the transmission side of the power ultrasound differences in the oscillation behavior as well as in the microstructure of the resulting joints could be detected.

\subsection{Oscillation Behavior}

\subsubsection{One-Dimensional Multi Point Vibrometry}

Compared to the other ultrasound assisted friction stir welding methods mentioned before, the USE-FSW process is unique because it uses a roll seam module, which transmits the power ultrasound continuously and in parallel to the FSW process into one of the metal sheets via its horn. The objective of this setup was to guarantee that a maximum oscillation of the metal sheets is always 
ensured at the welding zone. This assumption was investigated by transmitting power ultrasound into the steel sheet without superimposed FSW and measuring the one-dimensional oscillation behavior of the first eight measurement points located on the steel sheet near the butt joint via multi-point vibrometry. The measurement took place simultaneously for every measurement point over the whole time the horn was unrolling the distance of $200 \mathrm{~mm}$. Figure 3 shows the development of the oscillation amplitude for every measurement point in longitudinal direction depending on the current position of the unrolling horn.

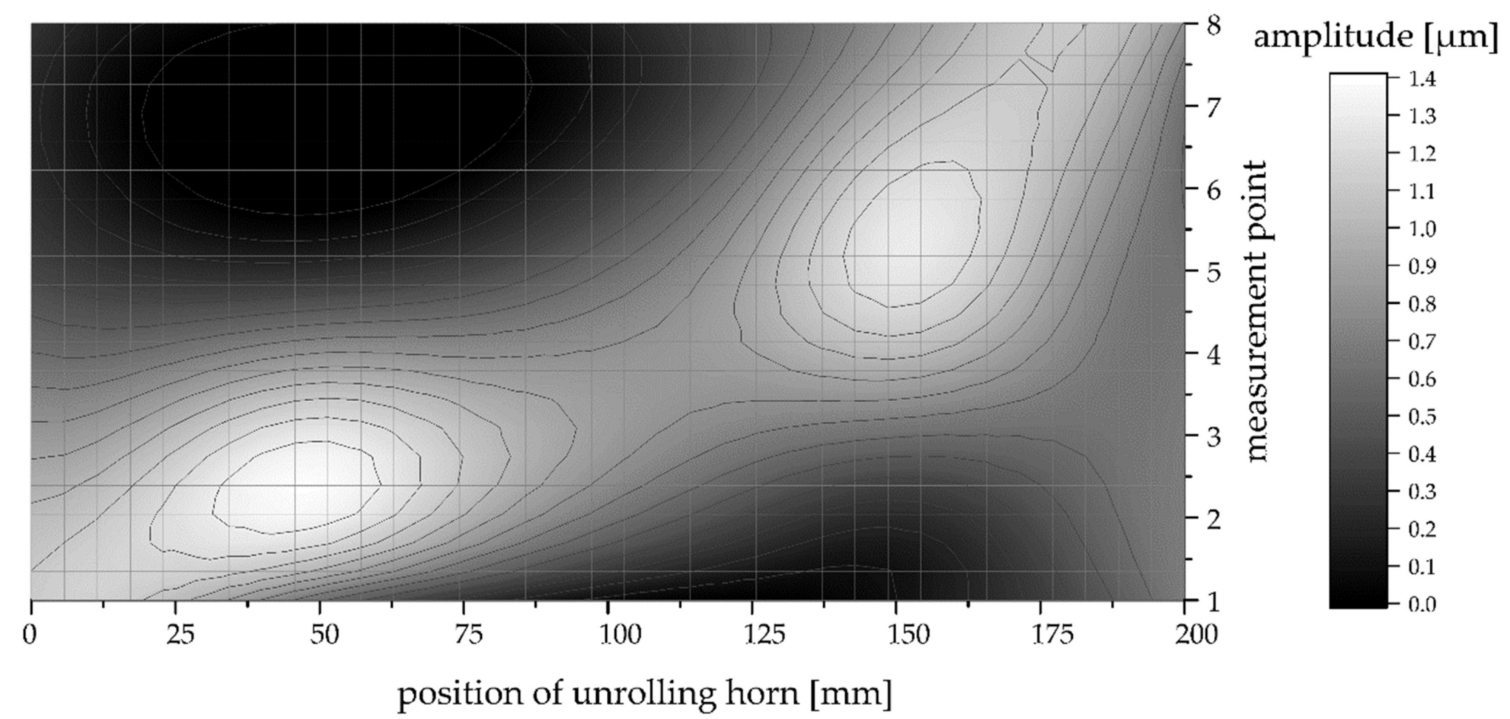

Figure 3. Development of oscillation amplitude depending on the current position of the horn.

The brighter areas in the contour plot represent higher amplitudes with a maximum of $1.4 \mu \mathrm{m}$, whereas the darker areas show very low to non-existing oscillation amplitudes. It is evident that the highest amplitudes at the adjacent measurement points correspond well with the advancing position of the unrolling horn as a diagonal line from the left front corner to the right rear corner could be drawn. This means there is always a maximum oscillation induced by the power ultrasound at the shortest distance between the horn and welding zone, and therewith verifies the functionality of the USE-FSW setup. The measurement points nine to sixteen located on the aluminum sheet did not show a significant oscillation behavior, so a correlation with the position of the unrolling horn was not possible.

\subsubsection{Three-Dimensional Scanning Vibrometry}

While ultrasonic metal welding is characterized by the tangential coupling of longitudinal waves into the joining partner that leads to the formation and propagation of transversal waves in the metal sheets, it is necessary to distinguish between longitudinal and transversal proportions of the oscillation to characterize the USE-FSW process in detail [30]. The PSV-500-3D scanning vibrometer enables a three-dimensional data acquisition of the scanning points and thus the distinction between these two waveforms. Figure 4 presents an overview of the conducted scanning vibrometry tests for the pre-process, where only power ultrasound was transmitted into one of the metal sheets via the horn. 


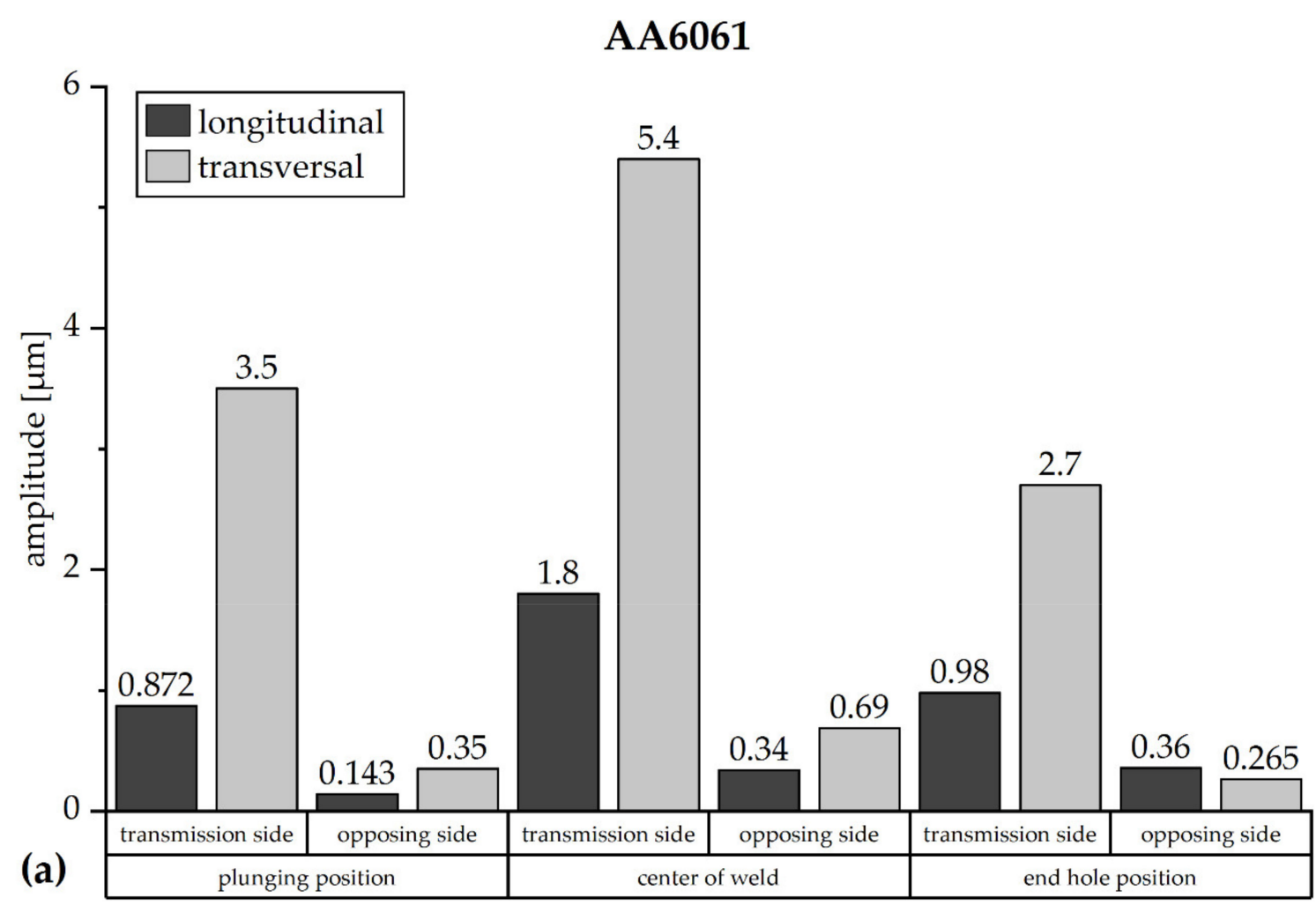

\section{DC04}

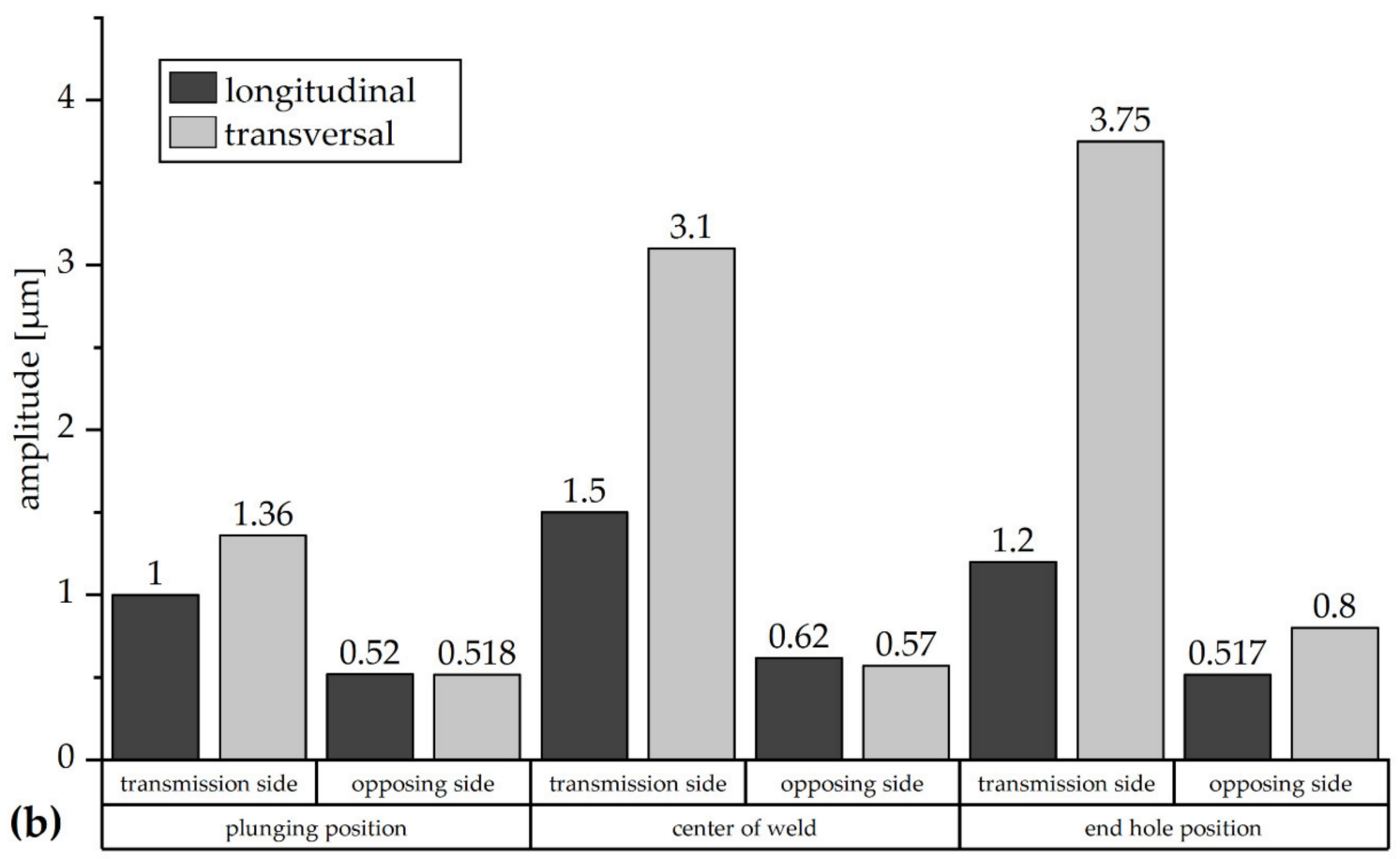

Figure 4. Proportions of longitudinal and transversal oscillations depending on the transmission position of the horn in (a) AA6061 and (b) DC04.

For the transmission of the power ultrasound into the aluminum sheet, Figure 4a shows an effect of the transmission position, where the plunging and end hole position achieve lower longitudinal oscillation amplitudes by only half the value as the center of the weld. This can be attributed to the 
four clamping claws fixating the joining partners in vertical direction, which were located next to the plunging and end hole position (lower oscillation amplitude) in comparison to the center of the weld without a clamping claw in direct surrounding (higher oscillation amplitude). Thus, the sheets exhibit a slightly higher degree of freedom at this center position in comparison to the plunging and end hole section. This effect is also visible qualitatively for the transversal proportion, whereas here the oscillations achieve higher amplitudes for the transmission positions by factors of 3 to 4 . The higher transversal values also can be explained by the aforementioned local vertical clamping at four fixation points causing increased level of freedom in vertical direction. Thereby, the resulting oscillation of up to nearly two microns in longitudinal direction is noteworthy, due to the full fixation of the sheets in horizontal directions. The metal sheet on the opposing side (in this case steel DC04) only gets stimulated by a very low oscillation amplitude, which can be attributed to the loss of power ultrasound by reflection and scattering at the faying surface and is in accordance to the investigations made with the multi point vibrometer before. Figure $4 \mathrm{~b}$ shows a similar oscillation behavior for the opposing side when power ultrasound was transmitted over the DC04. In addition, the dependency of the longitudinal ultrasound amplitude on the transmission position is qualitatively and quantitatively similar to that one when transmitting into aluminum and fits well to the amplitudes recorded with the multi point vibrometer before. A difference is given for the oscillation amplitude comparing the transversal proportions, whereas the transmission into steel resulted in lower amplitudes, and for the before detected dependency of the transmission positions the end hole position showed the highest value. This deviation from the position depending on findings before, which were explained by the position of the clamping claws, could be an outlier. In general the higher proportion of transversal oscillation amplitudes for the transmission of power ultrasound into aluminum can be explained by the higher hardness and stiffness of the AA6061 (112 HV10) compared to the DC04 (104 HV10), which is also mentioned by Tarasov et al. as beneficial for an optimized ultrasound transmission [29].

\subsection{Microstructure}

\section{Light Microscopy}

The influence of the power ultrasound compared to the conventional FSW and the transmission side of the power ultrasound on the microstructure of the joints was investigated via light microscopic imaging of cross sections of welded FSW and USE-FSW joints. Figure 5 shows a light microscopic image of an FSW AA6061/DC04 joint.

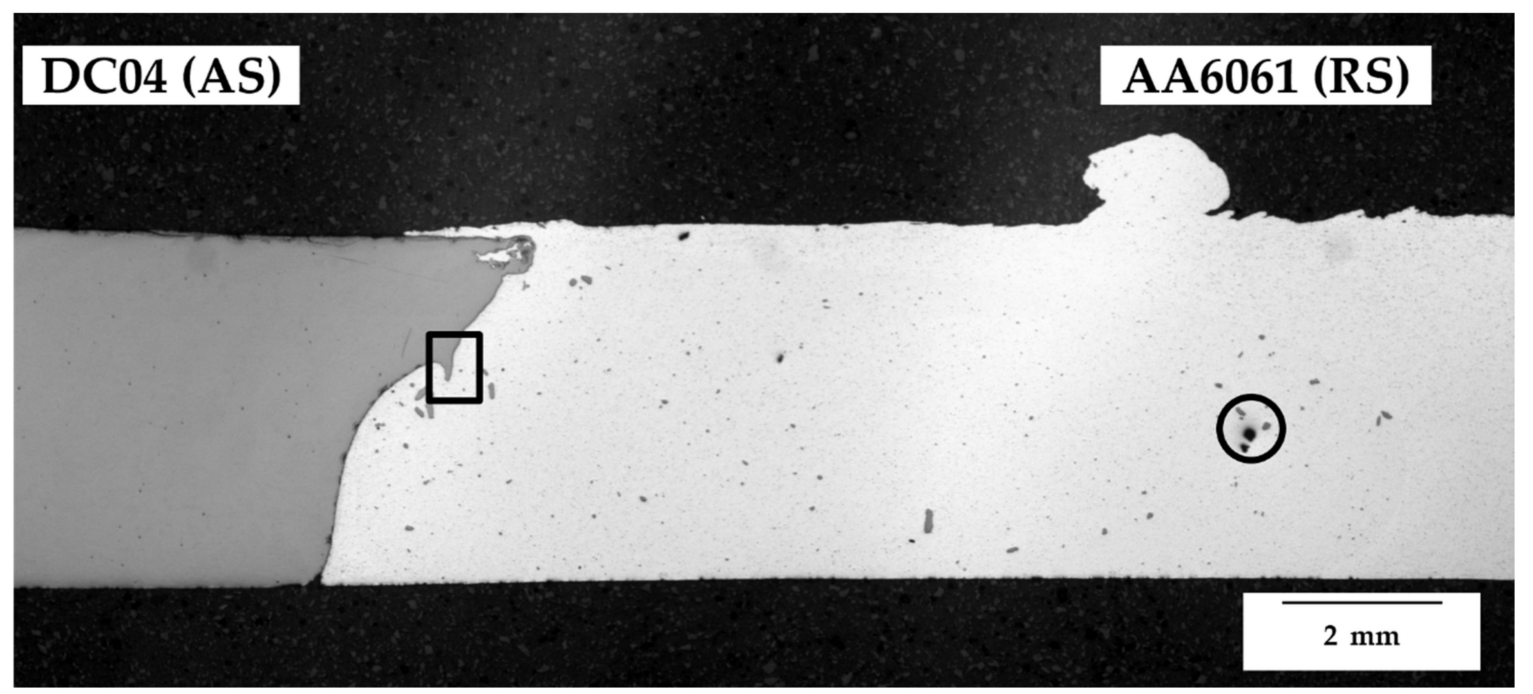

Figure 5. Cross section image of a Friction stir welding (FSW) AA6061/DC04 joint. 
Regarding the interface of the depicted joint a deformation of the steel surface in the upper third is visible, which appears to be stirred into the aluminum according to the selection of the advancing and retreating side. Additionally, a small hook (black box) originated at the end of the deformed area at the steel, which is typical for friction stir welded aluminum/steel joints $[9,14]$. The middle and lower part of the interface seem to be relatively unaffected by the FSW. This can be attributed to the specifically chosen offset of the probe into the aluminum, thus minimizing the mechanical contact between the probe and the steel surface. Furthermore, the stir zone, located next to the interface in the aluminum, contains of a comparatively low amount of steel particles, which originated from the steel joining partner, amounting to a volume fraction of $0.9 \%$. This is another indicator for the minimized contact between the probe and the steel. The verification for the origin of the steel particles from the DC04 base metal was provided in earlier work [31]. The transition area from stir zone to thermomechanical-affected zone contains a small pore (black circle). In comparison to the FSW joint, Figure 6 presents a USE-FSW AA6061/DC04 joint with ultrasound transmission via steel.

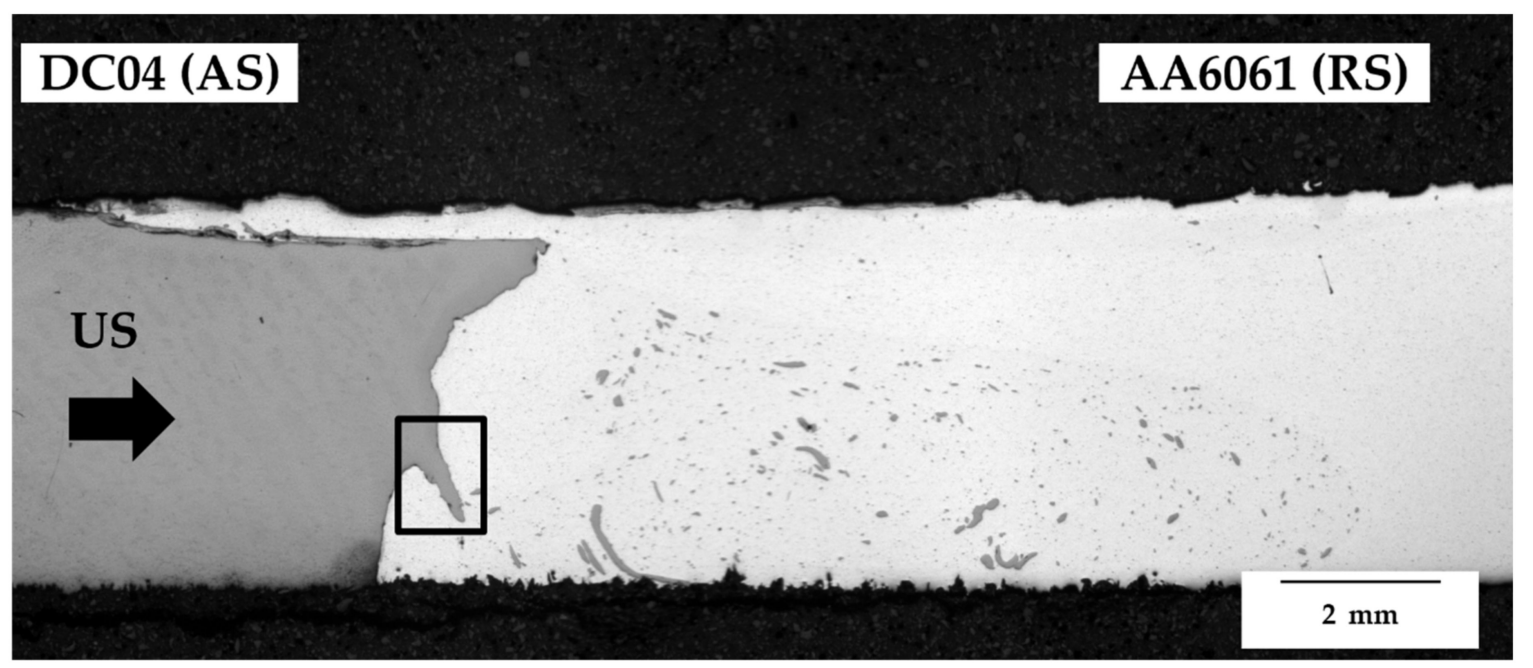

Figure 6. Cross section image of an ultrasound enhancement (USE-FSW) AA6061/DC04 joint with ultrasound transmission into steel.

The interface of the joint shows a more pronounced deformation over a broader area, covering about two-thirds of the whole thickness of the joint. The upper part of the interface again appears to be stirred into the aluminum the same way as for the FSW joint. In addition, the lower third of the interface zone appears to be plastically unaffected. However, in comparison to the conventional friction stir welded joint the developed steel hook (black box) is larger by a factor of about 4 to 5 . Furthermore, the sizes and amount of steel particles in the stir zone were increased strongly up to a volume fraction of $4 \%$, whereas it appears that the main amount is concentrated in the center and lower part. A weld defect such as the small pore in the FSW joint cannot be detected. These differences can be attributed to the effect of the power ultrasound transmitted over steel. The DC04 joining partner thereby got mechanically activated and, according to the pulse-pause-ratio, partially softened by the power ultrasound so that a broader deformation as well as the increased tearing of steel particles can take place. This is in accordance with the literature for Al/St joints [28,31]. Furthermore, Tian et al. could detect a similar but more pronounced effect of the ultrasound assistance transmitted via the tool for dissimilar Al/Cu joints [25]. They showed a significantly higher amount of copper in the stir zone when using lower rotational speeds, which can be attributed to the lower hardness of the copper in comparison to steel. In this work partially similar observations could be made for the USE-FSW AA6061/DC04 joint with ultrasound transmission via aluminum (Figure 7). 


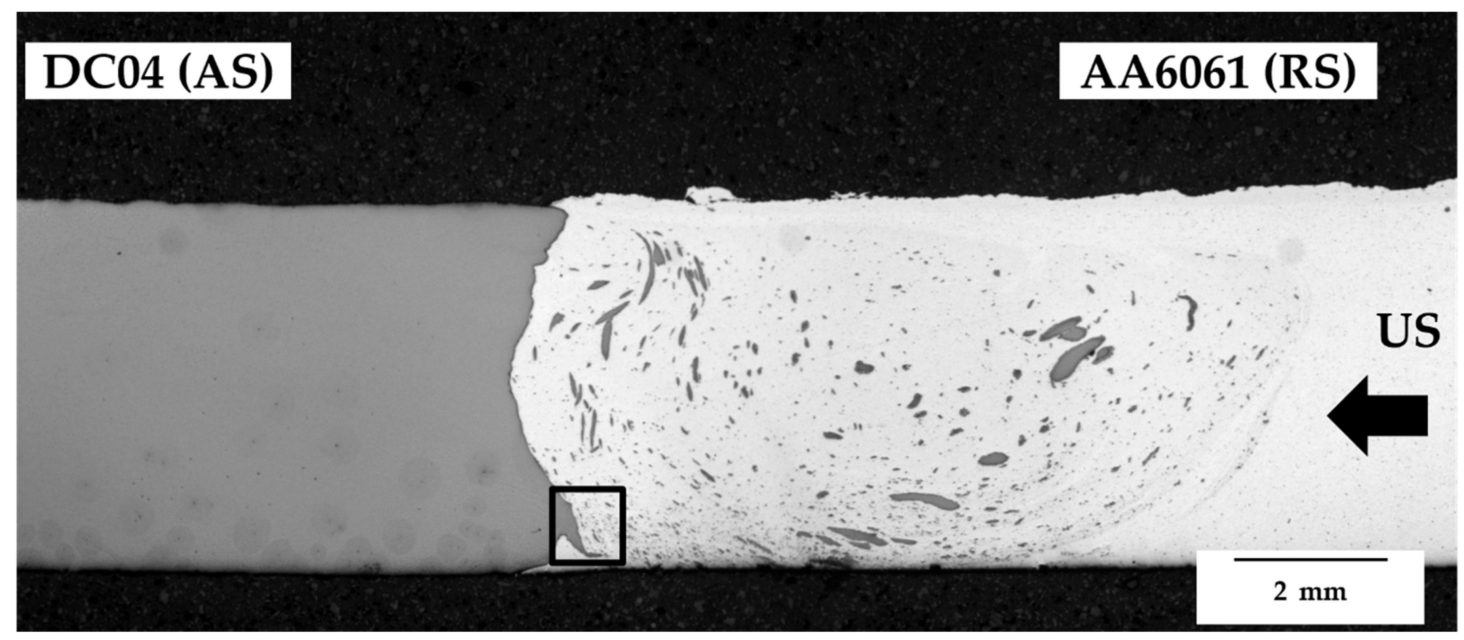

Figure 7. Cross section image of a USE-FSW AA6061/DC04 joint with ultrasound transmission into aluminum.

For this joint the interface between aluminum and steel appears to be deformed nearly uniformly over the whole thickness of the joint. Only a very small area at the root seems to be almost unaffected. The effect of the upper part of the steel joining partner being stirred into the aluminum noticed before is much less pronounced. Again, a hook, which is smaller than that for the USE-FSW joint realized by transmission of power ultrasound via steel, is visible at the lowest part of the deformed interface area (black box). The size of the steel particles in the stir zone again is notably increased and the volume fraction was more than doubled to a value of $8.5 \%$. In addition, for this ultrasound enhanced friction stir welded joint no weld defects could be observed. The swapping of the ultrasound transmission side can directly explain these different findings compared to the USE-FSW joint with transmission into steel. It appears that the power ultrasound again has an activating effect on the steel joining partner, whereas the different oscillation direction seems to push the stirred and plasticized aluminum more into the steel and against the natural flow direction of the steel caused by the selection of the advancing and retreating side. Furthermore, the increased transversal oscillation proportion when transmitting power ultrasound via aluminum seems to have a stronger impact on the resulting microstructure with the interface formation as well as the size and volume fraction of steel particles in the stir zone. Regarding the literature there was no published work, which could be compared due to the different power ultrasound transmission methods.

\section{Conclusions}

In the present work dissimilar AA6061/DC04 joints could be realized successfully by friction stir welding as well as ultrasound enhanced friction stir welding with varying transmission sides. The main findings can be summarized as follows:

(1) The functionality of the USE-FSW setup could be verified by one-dimensional multi point vibrometry measurements, that proved that the maximum oscillation is induced at the faying surfaces of the butt-joints within the shortest distance between the horn and weld zone.

(2) Transversal proportions of the oscillation behavior are higher for the AA6061, which can be attributed to the higher hardness and stiffness of the aluminum being beneficial for the ultrasound transmission.

(3) Ultrasound enhanced friction stir welded joints showed no weld defects such as pores at the transitional area of the stir zone to the thermomechanical-affected zone.

(4) The transmission of the power ultrasound via aluminum led to a microstructure with a more uniform interface as well as to a higher volume fraction of steel particles and an increase in the particle size. 
Author Contributions: Conceptualization, M.T. and G.W.; methodology, M.T., A.G., M.F. and G.W.; formal analysis, M.T., A.G. and G.W.; investigation, M.T., A.G., M.F.; resources, G.W.; writing-original draft preparation, M.T.; writing-review and editing, M.T., A.G., M.F. and G.W.; visualization, M.T. and A.G.; supervision, M.T. and G.W.; funding acquisition, M.T. and G.W. All authors have read and agreed to the published version of the manuscript.

Funding: The publication of this article was funded by Chemnitz University of Technology.

Acknowledgments: We thankfully acknowledge Dominik Hartmann, Master of Science, for his support during the research work.

Conflicts of Interest: The authors declare no conflict of interest.

\section{References}

1. Thomas, W.M.; Nicholas, E.D.; Needham, J.C.; Murch, M.G.; Templesmith, P.; Dawes, C.J. Friction Stir Welding EU Patent No. 0615480 B1, 1991.

2. Deutsches Institut für Normung e.V. Rührreibschweißen-Aluminium; Beuth Verlag GmbH: Berlin, Germany, 2012.

3. Gullino, A.; Matteis, P.; D'Aiuto, F. Review of Aluminum-To-Steel Welding Technologies for Car-Body Applications. Metals 2019, 9, 315. [CrossRef]

4. Mishra, R.S.; De, P.S.; Kumar, N. Friction Stir Welding and Processing; Springer International Publishing: Cham, Germany, 2014; ISBN 978-3-319-07042-1.

5. Park, S.-K.; Hong, S.-T.; Park, J.-H.; Park, K.-Y.; Kwon, Y.-J.; Son, H.-J. Effect of material locations on properties of friction stir welding joints of dissimilar aluminium alloys. Sci. Technol. Weld. Join. 2010, 15, 331-336. [CrossRef]

6. Leal, R.M.; Leitão, C.; Loureiro, A.; Rodrigues, D.M.; Vilaça, P. Material flow in heterogeneous friction stir welding of thin aluminium sheets: Effect of shoulder geometry. Mater. Sci. Eng. A 2008, 498, 384-391. [CrossRef]

7. Bergmann, J.P.; Schürer, R.; Ritter, K. Friction Stir Welding of Tailored Blanks of Aluminum and Magnesium Alloys. KEM 2013, 549, 492-499. [CrossRef]

8. Campo, K.N.; Campanelli, L.C.; Bergmann, L.; Santos, J.F.D.; Bolfarini, C. Microstructure and interface characterization of dissimilar friction stir welded lap joints between Ti-6Al-4V and AISI 304. Mater. Des. 2014, 56, 139-145. [CrossRef]

9. Wang, T.; Komarasamy, M.; Liu, K.; Mishra, R.S. Friction stir butt welding of strain-hardened aluminum alloy with high strength steel. Mater. Sci. Eng. A 2018, 737, 85-89. [CrossRef]

10. Dressler, U.; Biallas, G.; Alfaro Mercado, U. Friction stir welding of titanium alloy TiAl6V4 to aluminium alloy AA2024-T3. Mater. Sci. Eng. A 2009, 526, 113-117. [CrossRef]

11. Franke, D.J.; Morrow, J.D.; Zinn, M.R.; Pfefferkorn, F.E. Solid-State Infiltration of 6061-T6 Aluminum Alloy Into Carbon Fibers Via Friction Stir Welding. J. Manuf. Sci. Eng. 2017, 139, 679. [CrossRef]

12. Kusuda, Y. Honda develops robotized FSW technology to weld steel and aluminum and applied it to a mass-Production vehicle. Ind. Robot 2013, 40, 208-212. [CrossRef]

13. Okamoto, H. Desk Handbook. Phase Diagrams for Binary Alloys, 2nd ed.; ASM Internat: Materials Park, $\mathrm{OH}$, USA, 2010; ISBN 978-1-61503-046-0.

14. Watanabe, T.; Takayama, H.; Yanagisawa, A. Joining of aluminum alloy to steel by friction stir welding. J. Mater. Process. Technol. 2006, 178, 342-349. [CrossRef]

15. Martinsen, K.; Hu, S.J.; Carlson, B.E. Joining of dissimilar materials. CIRP Ann. 2015, 64, 679-699. [CrossRef]

16. Schubert, E.; Klassen, M.; Zerner, I.; Walz, C.; Sepold, G. Light-weight structures produced by laser beam joining for future applications in automobile and aerospace industry. J. Mater. Process. Technol. 2001, 115, 2-8. [CrossRef]

17. Gottstein, G. Materialwissenschaft Und Werkstofftechnik; Springer: Berlin, Germany, 2014; ISBN 978-3-642-36602-4.

18. Ferrando, W.A. The Concept of Electrically Assisted Friction Stir Welding (EAFSW) and Application to the Processing of Various Metals; Defense Technical Information Center: Fort Belvoir, VA, USA, 2008.

19. Merklein, M.; Giera, A. Laser assisted Friction Stir Welding of drawable steel-aluminium tailored hybrids. Int. J. Mater. 2008, 1, 1299-1302. [CrossRef] 
20. Bang, H.; Bang, H.; Jeon, G.; Oh, I.; Ro, C. Gas tungsten arc welding assisted hybrid friction stir welding of dissimilar materials Al6061-T6 aluminum alloy and STS304 stainless steel. Mater. Des. 2012, 37, 48-55. [CrossRef]

21. Klag, O.; Gröbner, J.; Wagner, G.; Schmid-Fetzer, R.; Eifler, D. Microstructural and thermodynamic investigations on friction stir welded Mg/Al-joints. IJMR 2014, 105, 145-155. [CrossRef]

22. Strass, B.; Wagner, G.; Conrad, C.; Wolter, B.; Benfer, S.; Fürbeth, W. Realization of Al/Mg-Hybrid-Joints by Ultrasound Supported Friction Stir Welding-Mechanical Properties, Microstructure and Corrosion Behavior. AMR 2014, 966-967, 521-535. [CrossRef]

23. Amini, S.; Amiri, M.R. Study of ultrasonic vibrations' effect on friction stir welding. Int. J. Adv. Manuf. Technol. 2014, 73, 127-135. [CrossRef]

24. Park, K. Development and Analysis of Ultrasonic Assisted Friction Stir Welding Process. Ph.D. Thesis, The University of Michigan, East Lansing, MI, USA, 2009.

25. Tian, W.; Su, H.; Wu, C. Effect of ultrasonic vibration on thermal and material flow behavior, microstructure and mechanical properties of friction stir welded Al/Cu joints. Int. J. Adv. Manuf. Technol. 2020, 107, 59-71. [CrossRef]

26. Liu, X.C.; Wu, C.S. Elimination of tunnel defect in ultrasonic vibration enhanced friction stir welding. Mater. Des. 2016, 90, 350-358. [CrossRef]

27. Tarasov, S.Y.; Rubtsov, V.Y.; Kolubaev, E.A.; Ivanov, A.N.; Fortuna, S.V.; Eliseev, A.A. Ultrasonic-assisted friction stir welding on V95AT1 (7075) aluminum alloy. In Ultrasonic-Assisted Friction Stir Welding on V95AT1 (7475) Aluminum Alloy, Advanced Materials with Hierarchical Structure for New Technologies and Reliable Structures; AIP Publishing LLC: Tomsk, Russia, 2015; p. 20231.

28. Thomä, M.; Gester, A.; Wagner, G.; Straß, B.; Wolter, B.; Benfer, S.; Gowda, D.K.; Fürbeth, W. Application of the hybrid process ultrasound enhanced friction stir welding on dissimilar aluminum/dual—Phase steel and aluminum/magnesium joints. Mater. Werkst. 2019, 50, 893-912. [CrossRef]

29. Tarasov, S.Y.; Rubtsov, V.E.; Fortuna, S.V.; Eliseev, A.A.; Chumaevsky, A.V.; Kalashnikova, T.A.; Kolubaev, E.A. Ultrasonic-assisted aging in friction stir welding on Al-Cu-Li-Mg aluminum alloy. Weld World 2017, 61, 679-690. [CrossRef]

30. Wodara, J.; Herold, H. Ultraschallfügen und Trennen; DVS-Verl: Düsseldorf, Germany, 2004; ISBN 3871552127.

31. Thomä, M.; Wagner, G.; Straß, B.; Wolter, B.; Benfer, S.; Fürbeth, W. Ultrasound enhanced friction stir welding of aluminum and steel: Process and properties of EN AW 6061/DC04-Joints. J. Mater. Sci. Technol. 2018, 34, 163-172. [CrossRef] 